\title{
Race Pattern of Women's 100-m Hurdles: Time Analysis of Olympic Hurdle Performance
}

\author{
Athanasios Tsiokanos ${ }^{1}$, Dimitrios Tsaopoulos ${ }^{2 *}$, Arsenis Giavroglou ${ }^{3}$, Eleftherios Tsarouchas ${ }^{3}$ \\ ${ }^{1}$ Department of Physical Education and Sports Science, Laboratory of Biomechanics, University of Thessaly, Trikala 42100, Greece \\ ${ }^{2}$ Institute for Research and Technology Thessaly (IRETETH), Kinesiology Sector, Center for Research and Technology Hellas (CERTH), \\ 51 Papanastasiou St, 41222, Larissa, Greece \\ ${ }^{3}$ Hellenic Sports Research Institute, OAKA, Kifisias 37, Maroussi 15123, Athens, Greece
}

Corresponding Author: Dimitrios Tsaopoulos, E-mail: dtsaop@gmail.com

\section{ARTICLE INFO}

Article history

Received: May 29, 2017

Accepted: July 18, 2017

Published: July 31, 2017

Volume: 5 Issue: 3

Conflicts of interest: None

Funding: None

\begin{abstract}
Background: For control and effective management of training process in women's $100-\mathrm{m}$ hurdles event, the coaches, in addition to detailed biomechanical parameters, need also overall, more comprehensive technical parameters, called direct performance descriptors which are used for planning the distribution of an athlete's efforts over the race. Purpose: The aim of this study was the investigation of the race behavior of elite women sprint hurdlers, on the basis of selected time parameters, and the examination of the existence of a common race pattern in high level hurdle performance. Method: The time data of the race performance between two consecutive Olympic Games were compared. The analyzing subjects consisted of all women 100-m hurdle finalists in Athens $2004(\mathrm{n}=6)$ and all women 100-m hurdle finalists $(\mathrm{n}=8)$ and semi-finalists $(n=14)$ in Beijing 2008. Results: No significant differences were revealed between the two competitions concerning to the means of approach run time, run-in time, intermediate touchdown times, interval times for the hurdle units and the corresponding average velocities. Significant relationship exists between the intermediate times and final performance. The time contribution of the first half of the race to the formation of the final performance is approximately equal to the second one and, generally the standardised time parameters show the existence of a common race pattern in high level hurdle performance. Conclusion: The presented biomechanical data provide coaches and athletes with valuable information about hurdle technique for effective interventions in the training process.
\end{abstract}

Key words: Biomechanics, Track and field, Hurdles, Competition analysis, Women athletes

\section{INTRODUCTION}

The women's 100-m hurdles event is a sprint race with ten altered steps needed to clear the barriers (McDonald \& Dapena, 1991b). Additionally to sprint velocity, the participant hurdlers is essential to have high level of technical skills, especially concerning the hurdle clearance phase. Therefore, most studies dealing with the technique of the above $100-\mathrm{m}$ hurdles event are focused on the analysis of kinematics (Ryu \& Chang, 2011; Iskra \& Coh, 2006; Stein, 2000; Wang \& Li, 2000; Salo, Grimshaw, \& Marar, 1997; Marar \& Grimshaw, 1993; McDonald \& Dapena, 1991a; Hücklekemkes, 1990) kinetics (McLean, 1994) and energetic characteristics (Ward-Smith, 1997) of the clearance phase. Moreover, There are few studies examining the effects of external conditions on sprint and hurdle performance (Yoshimoto, Takai \& Kanehisa, 2016; Hamlin, Hopkins \& Hollings, 2015), and a study examining the effects of early sport specialization on the development of a young athlete (Normand, Wolfe \& Peak, 2017).
However, for control and effective management of training process in hurdle events, the coaches, in addition to detailed biomechanical parameters describing the clearance phase and inter-hurdle distances (body kinematics, GRF, etc.), need also overall, more comprehensive technical parameters. These parameters (clearance times, horizontal velocity, split times, etc.,) that has been described as direct performance descriptors by Mann \& Herman (1985), are used for planning the distribution of an athlete's efforts over the race. For this purpose, the video techniques have established in the major competitions (Graubner \& Nixdorf, 2011; Mueller \& Hommel, 1997; Brüggemann \& Glad, 1990), to provide time parameters during clearance phase and inter-hurdle distances, and indirectly help for the calculation of average running velocities. Hence, with the further statistical analysis of the above parameters, that describe the efforts of world class athletes in the major competitions, theoretical models of effective running performance in hurdle events can be created. These kind of models offer valuable biomechanical informations to athletes and coaches, by

Published by Australian International Academic Centre PTY.LTD.

Copyright (c) the author(s). This is an open access article under CC BY license (https://creativecommons.org/licenses/by/4.0/)

http://dx.doi.org/10.7575/aiac.ijkss.v.5n.3p.56 
enabling the comparison of the statistical models with the data of a hurdler's individual performance in training, control or competition efforts, and by leading to the dynamic adaptation of various intervention method during the training process.

Video techniques analyses of hurdle performances have been carried out either with hurdlers as individuals, Olympic and world champions or world record holders (M Coh \& Dolenec, 1996; M Coh, 1987) or with a larger statistical sample of hurdlers (semi-finalists and finalists) included in research projects undertaken at the Olympic Games and IAAF world championships (Graubner \& Nixdorf, 2011; Mueller \& Hommel, 1997; Brüggemann \& Glad, 1990).

According to our knowledge only three biomechanical projects in IAAF world championships (Rome 1987, Athens 1997, Berlin 2009) and only one in Olympic Games (Seoul 1988) have examined the race pattern in high level hurdle performance and the race behavior of elite women sprint hurdlers. After the Olympic Games of Seoul there is no any time analysis study of hurdle performance with Olympic level hurdlers. Hence, the main purpose of this study was to obtain time parameters of 100-m female hurdlers on the basis of video techniques analyses curried out on two Olympic Games (Athens 2004 and Beijing 2008), in an attempt to compare time data of two consecutive Games and reexamine the race pattern of 100-m hurdle performance. Although the official time accuracy for this event is in $1 / 100 \mathrm{~s}$, all the previous time analyses are based on data collected with cameras recording at $50 \mathrm{~Hz}$. In the present study, the video cameras that selected for race recording, operated at $100 \mathrm{~Hz}$, providing the necessary accuracy in measurements. The fact that the present study concerns in earlier Olympiads does not mean that provide outdated information, because there is no essential performance improvement in the event at the last decade. Actually, conducting a performance comparison among the last four Olympic Games, as shown in table 1, there are neither any differences in the performance of the gold medalists, nor any significant differences among the mean performances of the hurdle finalists in the same Games. Additional aims of the present study were to enrich and update the databases with biomechanical parameters of elite female hurdlers, to provide coaches and athletes with quantitative information on individual techniques, and finally to investigate an existence of a common race pattern in high level hurdle performance.

\section{METHODS}

\section{Design and Participation}

The data was collected during the Olympic Games of Athens 2004 and Olympic Games of Beijing 2008. The analyzing

Table 1. Race performances (in seconds) at the last Olympic Games

\begin{tabular}{lcccc}
\hline & $\begin{array}{c}\text { Athens } \\
\mathbf{2 0 0 4}\end{array}$ & $\begin{array}{c}\text { Beijing } \\
\mathbf{2 0 0 8}\end{array}$ & $\begin{array}{c}\text { London } \\
\mathbf{2 0 1 2}\end{array}$ & Rio 2016 \\
\hline $1^{\text {st }}$ finalist & 12.37 & 12.54 & 12.35 & 12.48 \\
$\mathrm{M} \pm \mathrm{SD}$ & $12.61 \pm 0.17$ & $12.68 \pm 0.12$ & $12.60 \pm 0.24$ & $12.68 \pm 0.13$ \\
\hline
\end{tabular}

$\mathrm{M}=$ mean, $\mathrm{SD}=$ standard deviation subjects consisted of all women 100-m hurdle finalists in Athens $(n=6)$ and all women 100-m hurdle finalists $(n=8)$ and semi-finalists $(n=14)$ in Beijing. The efforts of all subjects in their final race were recording by three panned digital video cameras (JVC, GR-DVL 9600 model) with an operating rate of 100 frames per second. The video cameras were set above the spectator stands and were panned to record the sagittal view of the entire race, following the athletes from the start to the finish. The 1 st camera was positioned at the line of the $3^{\text {rd }}$ barrier recording mainly the take-off (TO) before and touchdown (TD) after $1^{\text {st }}, 2^{\text {nd }}$ and $3^{\text {rd }}$ barriers. The $2^{\text {nd }}$ camera was positioned at the line of the $7^{\text {th }}$ barrier recording mainly TO before and TD after $4^{\text {th }}, 5^{\text {th }}$, $6^{\text {th }}$ and $7^{\text {th }}$ barriers. The $3^{\text {rd }}$ camera was located at the line of the $10^{\text {th }}$ barrier recording mainly TO before and TD after $8^{\text {th }}$, $9^{\text {th }}$ and $10^{\text {th }}$ barriers. All three camcorders recorded the light signal of the gun, which represented the time of the start of the race, and was the zero point of the time measurements (starting point).

\section{Procedure}

In table 2 are presented and defined all variables analysed. All variables were based on video recordings and produced by calculating the passed frames between critical instants, via the Trim Module of the APAS (Ariel Dynamics Inc.). Intermediate times (TH1-10) were calculated from the start to TD of each hurdle. Hurdle unit's times (thu1-9) represent the interval times between two consecutive hurdle TDs. Approach run time is the interval time between the start and first hurdle TD minus the reaction time, while the run-in time is the final time minus the $10^{\text {th }}$ intermediate time. Clearance time represents the time between TO before and TD after each hurdle. Average velocities (Vthu1-9) were calculated by the covered distance $(8.50 \mathrm{~m})$ between two consecutive hurdles per corresponding hurdle unit time. For the velocity up to the first hurdle (VTH1) as covered distance was taken the distance from the start to first hurdle $(13.00 \mathrm{~m})$ plus $1.05 \mathrm{~m}$ to the TD after the hurdle (Mueller \& Hommel, 1997) and as time the intermediate time to first hurdle. For the runin velocity (Vtrin) as covered distance was taken the run-in distance $(10.50 \mathrm{~m})$ minus $1.05 \mathrm{~m}$ from the $10^{\text {th }}$ hurdle to the TD (Mueller \& Hommel, 1997) and as time the run-in time. The relative variables (RTH1, RTH2,.., RTH10, Rtar, Rtrin) were produced from the intermediate times divided by the final time (normalised by the final time). Finally the reaction time and the final time were provided by the official game chronometers.

\section{Statistical Analysis}

Statistical analysis, which was performed using SPSS version 18 (SPSS, Chicago, IL), included descriptives (mean, standard deviation), an independent t-test for comparison between Athens and Beijing variable means and a correlation analysis (a Pearson product-moment correlation coefficient) to evaluate relationships between final time and intermediate time variables. The alpha level of significance was set at $p<0.05$. All procedures performed in the study were in 
Table 2. Abbreviation and variable definitions

\begin{tabular}{|c|c|}
\hline RT & Reaction time \\
\hline THi & Time from the start to touchdown after the hurdle $\mathrm{i}(\mathrm{i}=1,2, \ldots, 10)$ \\
\hline FT & Final time at $100-\mathrm{m}$ \\
\hline thuj & $\begin{array}{l}\text { Time for the hurdle unit } \mathrm{j}(\mathrm{j}=1,2, \ldots, 9) \\
\text { (thu1=time interval between } 1^{\text {st }} \text { and } 2^{\text {nd }} \text { hurdle touchdown) } \\
\text { (thu2=time interval between } 2^{\text {nd }} \text { and } 3^{\text {rd }} \text { hurdle touchdown) }\end{array}$ \\
\hline & (thu9=time interval between 9 th and 10th hurdle touchdown) \\
\hline $\operatorname{tar}$ & $\begin{array}{l}\text { Approach run time } \\
\text { (time interval between the start and the } 1^{\text {st }} \text { hurdle touchdown minus the reaction time) }\end{array}$ \\
\hline trin & $\begin{array}{l}\text { Run-in time } \\
\text { (time interval between the } 10^{\text {th }} \text { hurdle touchdown and the final time) }\end{array}$ \\
\hline $\mathrm{CTi}$ & $\begin{array}{l}\text { Hurdle clearance time of the hurdle } \mathrm{i}(\mathrm{i}=1,2, \ldots, 10) \\
\text { (flight time from take-off before to touchdown after each hurdle) }\end{array}$ \\
\hline V- & $\begin{array}{l}\text { Estimated average velocity (VTH1, Vthu1, Vthu2, .., Vthu9, Vtrin) } \\
\text { (average velocity calculated by the covered distance per corresponding time) }\end{array}$ \\
\hline R- & $\begin{array}{l}\text { Relative variable (RTH1, RTH2, .. RTH10, Rtar, Rtrin) } \\
\text { (a variable normalised by the final time) }\end{array}$ \\
\hline
\end{tabular}

accordance with the ethical standards of the institutional research committee.

\section{RESULTS}

In tables $3 \mathrm{a}$ and $3 \mathrm{~b} 1$ are presented reaction time, final time and intermediate touchdown times of the finalists in Athens 2004 and Beijing 2008 respectively. In both cases the mean data shows that the greater differences between subjects occur in the second half of the race (greater variation of the standard deviation after $5^{\text {th }}$ hurdle). The comparison between Athens and Beijing didn't show any significant differences on the means of the above variables. But it could be seen a better reaction time in Athens 2004 than in Beijing 2008, and the same occurs about final time. In table $3 \mathrm{~b} 2$ are presented reaction time, final time and intermediate touchdown times of the semifinalists in Beijing. This is an additional sample of top women hurdlers, to enhance the study of the correlation coefficient between the final performance and intermediate times in Beijing Olympic Games.

In tables $4 \mathrm{a}$ and $4 \mathrm{~b}$ are presented approach run time, runin time and hurdle units' times of the finalists in Athens and Beijing respectively. On average, the hurdlers in Athens and Beijing accelerated from the start to $6^{\text {th }}$ hurdle, indicated by the decreasing hurdle units' times from unit 1 to unit 5 . The maximum achieved average velocity in Athens was $8.74 \mathrm{~m} / \mathrm{s}$ while in Beijing $8.75 \mathrm{~m} / \mathrm{s}$ (tables $6 \mathrm{a}$ and $6 \mathrm{~b}$ respectively).

In tables $5 \mathrm{a}$ and $5 \mathrm{~b}$ the hurdle clearance times show mean values from $0.28 \mathrm{~s}$ to $0.32 \mathrm{~s}$ in Athens and $0.29 \mathrm{~s}$ to $0.33 \mathrm{~s}$ in Beijing. The smallest individual value was $0.24 \mathrm{~s}$ and the biggest one $0.36 \mathrm{~s}$. A correlation analysis between the average clearance time of each hurdle and the final time, and also between the mean race clearance time of each athlete and the final time revealed no significant relationship between hurdle clearance time and race performance.

The mean values of relative temporal parameters (tables $7 \mathrm{a}$ and $7 \mathrm{~b}$ ) show a similar race pattern of hurdle finalists in both Olympic Games. It is of interest that the time contribution of the first half of the race is slightly larger than the second one (RTH5 $=0.516$ in both Games).

A correlation analysis between the temporal parameters and the final time (table 8 ) was conducted to identify the decisive points of the race. The analysis revealed no correlation between reaction time and final performance. Regarding to correlation between the final time and intermediate times, the analysis indicated that the size of correlation coefficients increases up to the last intermediate time (TH10), as has been expected. The approach run time showed significant correlation with the final time $(\mathrm{r}=0.57)$ only in analysis with Beijing's data. It is of great interest that after $6^{\text {th }}$ hurdle is determined $67 \%(r=0.82)$ of the variance of the final time. After the $10^{\text {th }}$ hurdle it is determined $94-96 \%(r=0.97$ and $\mathrm{r}=0.98$ ) of the above mentioned variance.

\section{DISCUSSION}

The aim of the present study, was 1) to compare the time data of the race performance between the $100-\mathrm{m}$ women hurdle finalists in two consecutive Olympic Games 2) to estimate the average velocities of the hurdlers in an attempt to observe their race behavior and their efforts' contribution during the race and 3) to investigate the existence of a common race pattern in high level hurdle performance.

\section{Reaction Time}

In regard to reaction time (RT), although there were no statistical differences between the two events, in Beijing 2008 was appeared greater mean value than in Athens $2004(0.176 \pm 0.031 \mathrm{~s}$ vs $0.161 \pm 0.019 \mathrm{~s})$, quite greater than the corresponding values in other $100-\mathrm{m}$ hurdle running finals in high level athletic events: In Olympics in Seoul 1988 with RT $=0.164 \pm 0.02$ s (Brüggemann \& Glad, 1990), in IAAF World Championships Athens 1997 with RT $=0.133 \pm 0.01 \mathrm{~s}$ (Mueller \& Hommel, 1997), and in IAAF World Championships Berlin 2009 with RT $=0.143 \pm 0.01 \mathrm{~s}$ (Graubner \& Nixdorf, 2011). Perhaps the finalists in Beijing 
Table 3a. Reaction time, final time and intermediate touchdown times (in seconds) in Olympics 2004

\begin{tabular}{|c|c|c|c|c|c|c|c|c|c|c|c|c|}
\hline & RT & TH1 & TH2 & TH3 & TH4 & TH5 & TH6 & TH7 & TH8 & TH9 & TH10 & FT \\
\hline Hayes J. (USA) & 0.169 & 2.52 & 3.53 & 4.50 & 5.45 & 6.42 & 7.36 & 8.32 & 9.29 & 10.27 & 11.28 & 12.37 \\
\hline Krasovska O. (UKR) & 0.151 & 2.55 & 3.55 & 4.55 & 5.51 & 6.48 & 7.45 & 8.41 & 9.39 & 10.37 & 11.36 & 12.45 \\
\hline Morrison M. (USA) & 0.145 & 2.56 & 3.54 & 4.50 & 5.48 & 6.47 & 7.48 & 8.47 & 9.47 & 10.47 & 11.47 & 12.56 \\
\hline Koroteyeva M. (RUS) & 0.195 & 2.61 & 3.64 & 4.63 & 5.64 & 6.61 & 7.57 & 8.56 & 9.57 & 10.58 & 11.61 & 12.72 \\
\hline Golding-Clarke (JAM) & 0.149 & 2.54 & 3.54 & 4.53 & 5.49 & 6.48 & 7.45 & 8.45 & 9.45 & 10.49 & 11.54 & 12.73 \\
\hline Whyte A. (CAN) & 0.155 & 2.56 & 3.59 & 4.58 & 5.57 & 6.57 & 7.56 & 8.53 & 9.55 & 10.61 & 11.64 & 12.81 \\
\hline M & 0.161 & 2.56 & 3.56 & 4.55 & 5.52 & 6.50 & 7.48 & 8.46 & 9.45 & 10.46 & 11.48 & 12.61 \\
\hline SD & 0.019 & 0.03 & 0.04 & 0.05 & 0.07 & 0.07 & 0.08 & 0.09 & 0.10 & 0.13 & 0.14 & 0.17 \\
\hline
\end{tabular}

$\mathrm{M}=$ mean, $\mathrm{SD}=$ standard deviation

Table 3b1. Reaction time, final time and intermediate touchdown times (in seconds) in final race of Olympics 2008

\begin{tabular}{|c|c|c|c|c|c|c|c|c|c|c|c|c|}
\hline & RT & TH1 & TH2 & TH3 & TH4 & TH5 & TH6 & TH7 & TH8 & ТH9 & TH10 & FT \\
\hline Harper D. (USA) & 0.193 & 2.55 & 3.59 & 4.53 & 5.51 & 6.50 & 7.46 & 8.45 & 9.44 & 10.43 & 11.44 & 12.54 \\
\hline McLellan S. (AUS) & 0.138 & 2.50 & 3.51 & 4.51 & 5.50 & 6.50 & 7.47 & 8.45 & 9.45 & 10.46 & 11.50 & 12.64 \\
\hline Lopes-Schliep. (CAN) & 0.174 & 2.57 & 3.63 & 4.63 & 5.60 & 6.60 & 7.58 & 8.54 & 9.53 & 10.56 & 11.58 & 12.64 \\
\hline Cherry D. (USA) & 0.239 & 2.63 & 3.66 & 4.67 & 5.64 & 6.61 & 7.59 & 8.56 & 9.55 & 10.55 & 11.58 & 12.65 \\
\hline Ennis-London (JAM) & 0.151 & 2.59 & 3.59 & 4.62 & 5.55 & 6.52 & 7.52 & 8.52 & 9.47 & 10.48 & 11.53 & 12.65 \\
\hline Foster-Hylton. (JAM) & 0.167 & 2.61 & 3.63 & 4.63 & 5.61 & 6.59 & 7.54 & 8.54 & 9.52 & 10.53 & 11.56 & 12.66 \\
\hline Jones L. (USA) & 0.185 & 2.57 & 3.53 & 4.50 & 5.44 & 6.44 & 7.38 & 8.34 & 9.32 & 10.37 & 11.46 & 12.72 \\
\hline Claxton S.(GBR) & 0.163 & 2.59 & 3.62 & 4.63 & 5.63 & 6.63 & 7.62 & 8.62 & 9.66 & 10.69 & 11.77 & 12.94 \\
\hline M & 0.176 & 2.58 & 3.59 & 4.59 & 5.56 & 6.55 & 7.52 & 8.50 & 9.49 & 10.51 & 11.55 & 12.68 \\
\hline SD & 0.031 & 0.04 & 0.05 & 0.07 & 0.07 & 0.07 & 0.08 & 0.09 & 0.10 & 0.10 & 0.10 & 0.12 \\
\hline
\end{tabular}

$\mathrm{M}=$ mean, $\mathrm{SD}=$ standard deviation

Table 3b2. Reaction time, final time and intermediate touchdown times (in seconds) in semi-final races of Olympics 2008

\begin{tabular}{|c|c|c|c|c|c|c|c|c|c|c|c|c|}
\hline & RT & TH1 & TH2 & TH3 & TH4 & TH5 & TH6 & TH7 & TH8 & TH9 & TH10 & FT \\
\hline Jones L. (USA) & 0.172 & 2.53 & 3.52 & 4.50 & 5.45 & 6.40 & 7.37 & 8.33 & 9.33 & 10.31 & 11.31 & 12.43 \\
\hline Ennis-London (JAM) & 0.145 & 2.56 & 3.58 & 4.56 & 5.55 & 6.54 & 7.49 & 8.46 & 9.47 & 10.49 & 11.51 & 12.67 \\
\hline Lopes-Schliep. (CAN) & 0.159 & 2.51 & 3.56 & 4.58 & 5.57 & 6.58 & 7.54 & 8.50 & 9.52 & 10.57 & 11.59 & 12.68 \\
\hline McLellan S. (AUS) & 0.140 & 2.54 & 3.55 & 4.54 & 5.53 & 6.51 & 7.51 & 8.52 & 9.52 & 10.54 & 11.57 & 12.70 \\
\hline Onyia J. (ESP) & 0.203 & 2.60 & 3.69 & 4.71 & 5.72 & 6.73 & 7.73 & 8.72 & 9.74 & 10.76 & 11.79 & 12.86 \\
\hline Trywianska-Kollasch. (POL) & 0.118 & 2.56 & 3.69 & 4.70 & 5.72 & 6.73 & 7.75 & 8.75 & 9.76 & 10.79 & 11.84 & 12.96 \\
\hline Nytra C. (GER) & 0.144 & 2.60 & 3.63 & 4.66 & 5.67 & 6.68 & 7.70 & 8.73 & 9.75 & 10.79 & 11.87 & 12.99 \\
\hline Yanit N. (TUR) & 0.201 & 2.62 & 3.68 & 4.70 & 5.72 & 6.73 & 7.76 & 8.81 & 9.87 & 11.10 & 12.19 & 13.28 \\
\hline Cherry D. (USA) & 0.189 & 2.59 & 3.62 & 4.59 & 5.55 & 6.52 & 7.52 & 8.52 & 9.52 & 10.52 & 11.54 & 12.62 \\
\hline Harper D. (USA) & 0.191 & 2.58 & 3.58 & 4.55 & 5.54 & 6.52 & 7.48 & 8.45 & 9.45 & 10.49 & 11.52 & 12.66 \\
\hline Foster-Hylton. (JAM) & 0.162 & 2.61 & 3.65 & 4.66 & 5.66 & 6.61 & 7.59 & 8.59 & 9.60 & 10.62 & 11.66 & 12.76 \\
\hline Claxton S. (GBR) & 0.145 & 2.57 & 3.60 & 4.59 & 5.58 & 6.53 & 7.53 & 8.53 & 9.55 & 10.61 & 11.66 & 12.84 \\
\hline Dixon V. (JAM) & 0.237 & 2.61 & 3.64 & 4.64 & 5.65 & 6.74 & 7.77 & 8.76 & 9.76 & 10.75 & 11.78 & 12.86 \\
\hline Okori R.F. (FRA) & 0.153 & 2.63 & 3.70 & 4.65 & 5.71 & 6.73 & 7.74 & 8.77 & 9.80 & 10.84 & 11.89 & 13.05 \\
\hline M & 0.168 & 2.58 & 3.62 & 4.62 & 5.62 & 6.61 & 7.61 & 8.60 & 9.62 & 10.66 & 11.69 & 12.81 \\
\hline SD & 0.032 & 0.04 & 0.06 & 0.07 & 0.09 & 0.11 & 0.13 & 0.15 & 0.16 & 0.20 & 0.22 & 0.21 \\
\hline
\end{tabular}

$\mathrm{M}=$ mean, $\mathrm{SD}=$ standard deviation

have been more cautious in response to the start, and the reason was the track and field's zero-tolerance false start policy. Also, the finding of the present study that there is no any statistically significant correlation between the reaction time and the final performance is consistent with the results of similar studies on elite women hurdlers (Graubner 
Table 4a. Approach run time, run-in time, hurdle units' times (in seconds) in Olympics 2004

\begin{tabular}{lccccccccccc}
\hline & tar & thu1 & thu2 & thu3 & thu4 & thu5 & thu6 & thu7 & thu8 & thu9 & trin \\
\hline Hayes J. (USA) & 2.35 & 1.01 & 0.97 & 0.95 & 0.97 & 0.94 & 0.96 & 0.97 & 0.98 & 1.01 & 1.09 \\
Krasovska O. (UKR) & 2.40 & 1.00 & 1.00 & 0.96 & 0.97 & 0.97 & 0.96 & 0.98 & 0.98 & 0.99 & 1.09 \\
Morrison M. (USA) & 2.42 & 0.98 & 0.96 & 0.98 & 0.99 & 1.01 & 0.99 & 1.00 & 1.00 & 1.00 & 1.09 \\
Koroteyeva M. (RUS) & 2.42 & 1.03 & 0.99 & 1.01 & 0.97 & 0.96 & 0.99 & 1.01 & 1.01 & 1.03 & 1.11 \\
Golding-Clarke (JAM) & 2.39 & 1.00 & 0.99 & 0.96 & 0.99 & 0.97 & 1.00 & 1.00 & 1.04 & 1.05 & 1.19 \\
Whyte A. (CAN) & 2.41 & 1.03 & 0.99 & 0.99 & 1.00 & 0.99 & 0.97 & 1.02 & 1.06 & 1.03 & 1.17 \\
M & 2.40 & 1.01 & 0.98 & 0.97 & 0.98 & 0.97 & 0.98 & 1.00 & 1.01 & 1.02 & 1.12 \\
SD & 0.02 & 0.02 & 0.01 & 0.02 & 0.01 & 0.02 & 0.02 & 0.02 & 0.03 & 0.02 & 0.05 \\
\hline
\end{tabular}

$\mathrm{M}=$ mean, $\mathrm{SD}=$ standard deviation

Table 4b. Approach run time, run-in time, hurdle units' times (in seconds) in Olympics 2008

\begin{tabular}{lccccccccccc}
\hline & tar & thu1 & thu2 & thu3 & thu4 & thu5 & thu6 & thu7 & thu8 & thu9 & trin \\
\hline Harper D. (USA) & 2.36 & 1.04 & 0.94 & 0.98 & 0.99 & 0.96 & 0.99 & 0.99 & 0.99 & 1.01 & 1.10 \\
McLellan S. (AUS) & 2.36 & 1.01 & 1.00 & 0.99 & 1.00 & 0.97 & 0.98 & 1.00 & 1.01 & 1.04 & 1.14 \\
Lopes-Schliep. (CAN) & 2.40 & 1.06 & 1.00 & 0.97 & 1.00 & 0.98 & 0.96 & 0.99 & 1.03 & 1.02 & 1.06 \\
Cherry D. (USA) & 2.39 & 1.03 & 1.01 & 0.97 & 0.97 & 0.98 & 0.97 & 0.99 & 1.00 & 1.03 & 1.07 \\
Ennis-London (JAM) & 2.44 & 1.00 & 1.03 & 0.93 & 0.97 & 1.00 & 1.00 & 0.95 & 1.01 & 1.05 & 1.12 \\
Foster-Hylton. (JAM) & 2.44 & 1.02 & 1.00 & 0.98 & 0.98 & 0.95 & 1.00 & 0.98 & 1.01 & 1.03 & 1.10 \\
Jones L. (USA) & 2.39 & 0.96 & 0.97 & 0.94 & 1.00 & 0.94 & 0.96 & 0.98 & 1.05 & 1.09 & 1.26 \\
Claxton S.(GBR) & 2.43 & 1.03 & 1.01 & 1.00 & 1.00 & 0.99 & 1.00 & 1.04 & 1.03 & 1.08 & 1.17 \\
M & 2.40 & 1.02 & 0.99 & 0.97 & 0.99 & 0.97 & 0.98 & 0.99 & 1.02 & 1.04 & 1.13 \\
SD & 0.03 & 0.03 & 0.03 & 0.02 & 0.01 & 0.02 & 0.02 & 0.02 & 0.02 & 0.03 & 0.06 \\
\hline
\end{tabular}

$\mathrm{M}=$ mean, $\mathrm{SD}=$ standard deviation

Table 5a. Clearance times (in seconds) in Olympics 2004

\begin{tabular}{lcccccccccc}
\hline & CT1 & CT2 & CT3 & CT4 & CT5 & CT6 & CT7 & CT8 & CT9 & CT10 \\
\hline Hayes J. (USA) & 0.32 & 0.32 & 0.31 & 0.28 & 0.30 & 0.28 & 0.28 & 0.29 & 0.30 & 0.31 \\
Krasovska O. (UKR) & 0.30 & 0.26 & 0.27 & 0.27 & 0.29 & 0.29 & 0.27 & 0.27 & 0.30 & 0.29 \\
Morrison M. (USA) & 0.35 & 0.33 & 0.33 & 0.33 & 0.31 & 0.33 & 0.30 & 0.34 & 0.36 & 0.33 \\
Koroteyeva M. (RUS) & 0.30 & 0.33 & 0.32 & 0.31 & 0.32 & 0.30 & 0.27 & 0.28 & 0.31 & 0.31 \\
Golding-Clarke (JAM) & 0.30 & 0.31 & 0.32 & 0.28 & 0.31 & 0.31 & 0.31 & 0.32 & 0.33 & 0.33 \\
Whyte A. (CAN) & 0.26 & 0.29 & 0.29 & 0.28 & 0.30 & 0.28 & 0.28 & 0.28 & 0.30 & 0.30 \\
M & 0.30 & 0.31 & 0.31 & 0.29 & 0.30 & 0.30 & 0.28 & 0.30 & 0.32 & 0.31 \\
SD & 0.03 & 0.03 & 0.02 & 0.02 & 0.01 & 0.02 & 0.02 & 0.03 & 0.02 & 0.02 \\
\hline
\end{tabular}

$\mathrm{M}=$ mean, $\mathrm{SD}=$ standard deviation

\& Nixdorf, 2011; Mueller \& Hommel, 1997; Brüggemann \& Glad, 1990). But, generally, in high level sprint running, a short reaction time is considered as a prerequisite for successful performance.

\section{Approach Run Phase}

The approach run time was the same in both Games $(2.40 \pm 0.02 \mathrm{~s}$ vs $2.40 \pm 0.03 \mathrm{~s})$, nevertheless of the greater final time in Beijing $2008(\mathrm{FT}=12.68 \pm 0.12 \mathrm{~s})$ than in Athens $2004(\mathrm{FT}=12.61 \pm 0.17 \mathrm{~s})$, and also the corresponding relative quantities appeared approximately the same value $(\operatorname{Rtar}=0.190 \pm 0.002 \mathrm{~s}$ in Athens $2004 \mathrm{vs}$
$0.189 \pm 0.002 \mathrm{~s}$ in Beijing 2008). This fact means that the tar contributes $19 \%$ to the formation of final performance. In the present study the time up to the first hurdle was $2.56 \pm 0.03 \mathrm{~s}$ vs $2.58 \pm 0.04 \mathrm{~s}$ (respectively for Athens and Beijing) and was at the same level with other studies (Graubner \& Nixdorf, 2011; Mueller \& Hommel, 1997; Brüggemann \& Glad, 1990), representing a mean velocity of $5.44-5.49 \mathrm{~m} / \mathrm{s}$.

\section{Intermediate Touchdown and Hurdle Units Times}

The findings of the present study that hurdle finalists accelerate from the start to $6^{\text {th }}$ hurdle are in agreement with other studies (Graubner \& Nixdorf, 2011; Mueller \& Hom- 
Table 5b. Clearance times (in seconds) in Olympics 2008

\begin{tabular}{lllllllllll}
\hline & CT1 & CT2 & CT3 & CT4 & CT5 & CT6 & CT7 & CT8 & CT9 & CT10 \\
\hline Harper D. (USA) & 0.28 & 0.30 & 0.27 & 0.25 & 0.30 & 0.28 & 0.27 & 0.30 & 0.30 & 0.32 \\
McLellan S. (AUS) & 0.39 & 0.29 & 0.31 & 0.31 & 0.32 & 0.29 & 0.29 & 0.29 & 0.32 & 0.32 \\
Lopes-Schliep. (CAN) & 0.32 & 0.37 & 0.34 & 0.30 & 0.34 & 0.34 & 0.31 & 0.33 & 0.35 & 0.35 \\
Cherry D. (USA) & 0.33 & 0.31 & 0.35 & 0.33 & 0.32 & 0.32 & 0.31 & 0.29 & 0.28 & 0.32 \\
Ennis-London (JAM) & 0.33 & 0.28 & 0.34 & 0.28 & 0.29 & 0.34 & 0.33 & 0.29 & 0.31 & 0.34 \\
Foster-Hylton. (JAM) & 0.30 & 0.28 & 0.34 & 0.27 & 0.31 & 0.34 & 0.30 & 0.30 & 0.31 & 0.32 \\
Jones L. (USA) & 0.30 & 0.30 & 0.31 & 0.28 & 0.31 & 0.29 & 0.28 & 0.28 & 0.36 & 0.35 \\
Claxton S.(GBR) & 0.30 & 0.32 & 0.34 & 0.32 & 0.31 & 0.24 & 0.25 & 0.33 & 0.33 & 0.34 \\
M & 0.32 & 0.31 & 0.32 & 0.29 & 0.31 & 0.30 & 0.29 & 0.30 & 0.32 & 0.33 \\
SD & 0.03 & 0.03 & 0.03 & 0.03 & 0.01 & 0.04 & 0.02 & 0.02 & 0.03 & 0.01 \\
\hline
\end{tabular}

$\mathrm{M}=$ mean, $\mathrm{SD}=$ standard deviation.

Table 6a. Approach run velocity, run-in velocity, hurdle units' velocities (in m/s) in Olympics 2004

\begin{tabular}{lccccccccccc}
\hline & VTH1 & Vthu1 & Vthu2 & Vthu3 & Vthu4 & Vthu5 & Vthu6 & Vthu7 & Vthu8 & Vthu9 & Vtrin \\
\hline Hayes J. (USA) & 6.05 & 8.42 & 8.76 & 8.95 & 8.76 & 9.04 & 8.85 & 8.76 & 8.67 & 8.42 & 8.50 \\
Krasovska O. (UKR) & 5.93 & 8.50 & 8.50 & 8.85 & 8.76 & 8.76 & 8.85 & 8.67 & 8.67 & 8.59 & 8.50 \\
Morrison M. (USA) & 5.89 & 8.67 & 8.85 & 8.67 & 8.59 & 8.42 & 8.59 & 8.50 & 8.50 & 8.50 & 8.50 \\
Koroteyeva M. (RUS) & 5.89 & 8.25 & 8.59 & 8.42 & 8.76 & 8.85 & 8.59 & 8.42 & 8.42 & 8.25 & 8.35 \\
Golding-Clarke (JAM) & 5.95 & 8.50 & 8.59 & 8.85 & 8.59 & 8.76 & 8.50 & 8.50 & 8.17 & 8.10 & 7.79 \\
Whyte A. (CAN) & 5.92 & 8.25 & 8.59 & 8.59 & 8.50 & 8.59 & 8.76 & 8.33 & 8.02 & 8.25 & 7.92 \\
M & 5.86 & 8.43 & 8.65 & 8.72 & 8.66 & 8.74 & 8.69 & 8.53 & 8.41 & 8.35 & 8.42 \\
SD & 0.06 & 0.16 & 0.13 & 0.20 & 0.12 & 0.22 & 0.15 & 0.16 & 0.27 & 0.18 & 0.33 \\
\hline
\end{tabular}

$\mathrm{M}=$ mean, $\mathrm{SD}=$ standard deviation.

Table 6b. Approach run velocity, run-in velocity, hurdle units' velocities (in m/s) in Olympics 2008

\begin{tabular}{lccccccccccc}
\hline & VTH1 & Vthu1 & Vthu2 & Vthu3 & Vthu4 & Vthu5 & Vthu6 & Vthu7 & Vthu8 & Vthu9 & Vtrin \\
\hline Harper D. (USA) & 5.95 & 8.17 & 9.04 & 8.67 & 8.59 & 8.85 & 8.59 & 8.59 & 8.59 & 8.42 & 8.43 \\
McLellan S. (AUS) & 5.95 & 8.42 & 8.50 & 8.59 & 8.50 & 8.76 & 8.67 & 8.50 & 8.42 & 8.17 & 8.13 \\
Lopes-Schliep. (CAN) & 5.85 & 8.02 & 8.50 & 8.76 & 8.50 & 8.67 & 8.85 & 8.59 & 8.25 & 8.33 & 8.75 \\
Cherry D. (USA) & 5.88 & 8.25 & 8.42 & 8.76 & 8.76 & 8.67 & 8.76 & 8.59 & 8.50 & 8.25 & 8.66 \\
Ennis-London (JAM) & 5.76 & 8.50 & 8.25 & 9.14 & 8.76 & 8.50 & 8.50 & 8.95 & 8.42 & 8.10 & 8.28 \\
Foster-Hylton. (JAM) & 5.76 & 8.33 & 8.50 & 8.67 & 8.67 & 8.95 & 8.50 & 8.67 & 8.42 & 8.25 & 8.43 \\
Jones L. (USA) & 5.88 & 8.85 & 8.76 & 9.04 & 8.50 & 9.04 & 8.85 & 8.67 & 8.10 & 7.80 & 7.36 \\
Claxton S.(GBR) & 5.78 & 8.25 & 8.42 & 8.50 & 8.50 & 8.59 & 8.50 & 8.17 & 8.25 & 7.87 & 7.92 \\
M & 5.85 & 8.35 & 8.55 & 8.77 & 8.60 & 8.75 & 8.65 & 8.59 & 8.37 & 8.15 & 8.24 \\
SD & 0.08 & 0.25 & 0.24 & 0.22 & 0.12 & 0.18 & 0.15 & 0.21 & 0.16 & 0.22 & 0.45 \\
\hline
\end{tabular}

$\mathrm{M}=$ mean, $\mathrm{SD}=$ standard deviation.

mel, 1997; Brüggemann \& Glad, 1990). The greater average velocity achieved between hurdles in the present study is $8.74 \mathrm{~m} / \mathrm{s}$ (Athens 2004) or $8.75 \mathrm{~m} / \mathrm{s}$ (Beijing 2008) and is similar to that from other studies $(8.73 \mathrm{~m} / \mathrm{s}$ in Athens 1997 , $8.74 \mathrm{~m} / \mathrm{s}$ in Berlin 2009) (Graubner \& Nixdorf, 2011; Mueller \& Hommel, 1997). In Seoul 1988 the biggest average velocity was only $8.67 \mathrm{~m} / \mathrm{s}$ (corresponding to a mean time of $0.98 \mathrm{~s}$ at the $5^{\text {th }}$ hurdle unit). These velocities are much lower than the maximum velocities $(10.29-10.72 \mathrm{~m} / \mathrm{s})$ observed in the $100 \mathrm{~m}$ sprint (Mueller \& Hommel, 1997). After the achievement of maximum velocity, follows a decline of the running velocity at the next hurdle units up to the last hurdle. It is important for a hurdle runner to minimise the velocity decline. The minimum velocity decline the maximum specific running endurance. In Athens 2004 the average decline of the velocity from the $6^{\text {th }}$ hurdle to the $10^{\text {th }}$ was the $4.46 \%$ of the maximum velocity, and the corresponding decline in Beijing 2008 was $6.86 \%$ of the maximum.

Regarding to correlation between the final time and intermediate times, the analysis revealed significant relationship between the final performance and touchdown times from the $5^{\text {th }}$ hurdle to $10^{\text {th }}$ hurdle in both Games, with gradually 
Table 7a. Relative temporal parameters in Olympics 2004

\begin{tabular}{lccccccccccc}
\hline & RTH1 & RTH2 & RTH3 & RTH4 & RTH5 & RTH6 & RTH7 & RTH8 & RTH9 & RTH10 & Rtar \\
\hline Hayes J. (USA) & 0.204 & 0.285 & 0.364 & 0.441 & 0.519 & 0.595 & 0.673 & 0.751 & 0.830 & 0.912 & 0.190 \\
Krasovska O. (UKR) & 0.205 & 0.285 & 0.365 & 0.443 & 0.520 & 0.598 & 0.676 & 0.754 & 0.833 & 0.912 & 0.193 \\
Morrison M. (USA) & 0.204 & 0.282 & 0.358 & 0.436 & 0.515 & 0.596 & 0.674 & 0.754 & 0.834 & 0.913 & 0.192 \\
Koroteyeva M. (RUS) & 0.205 & 0.286 & 0.364 & 0.443 & 0.520 & 0.595 & 0.673 & 0.752 & 0.832 & 0.913 & 0.190 \\
Golding-Clarke (JAM) & 0.200 & 0.278 & 0.356 & 0.431 & 0.509 & 0.585 & 0.664 & 0.742 & 0.824 & 0.907 & 0.188 \\
Whyte A. (CAN) & 0.200 & 0.280 & 0.358 & 0.435 & 0.513 & 0.590 & 0.666 & 0.746 & 0.828 & 0.909 & 0.188 \\
M & 0.203 & 0.283 & 0.361 & 0.438 & 0.516 & 0.593 & 0.671 & 0.750 & 0.830 & 0.911 & 0.190 \\
SD & 0.002 & 0.003 & 0.004 & 0.005 & 0.004 & 0.005 & 0.005 & 0.005 & 0.004 & 0.003 & 0.002 \\
\hline
\end{tabular}

$\mathrm{M}=$ mean, $\mathrm{SD}=$ standard deviation.

Table 7b. Relative temporal parameters in Olympics 2008

\begin{tabular}{lccccccccccc}
\hline & RTH1 & RTH2 & RTH3 & RTH4 & RTH5 & RTH6 & RTH7 & RTH8 & RTH9 & RTH10 & Rtar \\
\hline Harper D. (USA) & 0.203 & 0.286 & 0.361 & 0.439 & 0.518 & 0.595 & 0.674 & 0.753 & 0.832 & 0.912 & 0.188 \\
McLellan S. (AUS) & 0.198 & 0.278 & 0.357 & 0.435 & 0.514 & 0.591 & 0.669 & 0.748 & 0.828 & 0.910 & 0.187 \\
Lopes-Schliep. (CAN) & 0.203 & 0.287 & 0.366 & 0.443 & 0.522 & 0.600 & 0.676 & 0.754 & 0.835 & 0.916 & 0.190 \\
Cherry D. (USA) & 0.208 & 0.289 & 0.369 & 0.446 & 0.523 & 0.600 & 0.677 & 0.755 & 0.834 & 0.915 & 0.189 \\
Ennis-London (JAM) & 0.205 & 0.284 & 0.365 & 0.439 & 0.515 & 0.594 & 0.674 & 0.749 & 0.828 & 0.911 & 0.193 \\
Foster-Hylton. (JAM) & 0.206 & 0.287 & 0.366 & 0.443 & 0.521 & 0.596 & 0.675 & 0.752 & 0.832 & 0.913 & 0.193 \\
Jones L. (USA) & 0.202 & 0.278 & 0.354 & 0.428 & 0.506 & 0.580 & 0.656 & 0.733 & 0.815 & 0.901 & 0.188 \\
Claxton S. (GBR) & 0.200 & 0.280 & 0.358 & 0.435 & 0.512 & 0.589 & 0.666 & 0.747 & 0.826 & 0.910 & 0.188 \\
M & 0.203 & 0.283 & 0.362 & 0.438 & 0.516 & 0.593 & 0.671 & 0.749 & 0.829 & 0.911 & 0.189 \\
SD & 0.003 & 0.005 & 0.005 & 0.006 & 0.005 & 0.006 & 0.007 & 0.007 & 0.006 & 0.005 & 0.002 \\
\hline
\end{tabular}

$\mathrm{M}=$ mean, $\mathrm{SD}=$ standard deviation.

Table 8. Correlation coefficients between final time and temporal parameters

\begin{tabular}{|c|c|c|c|c|c|c|c|c|c|c|c|c|c|c|}
\hline & & RT & TH1 & TH2 & TH3 & TH4 & TH5 & TH6 & TH7 & TH8 & TH9 & TH10 & $\operatorname{tar}$ & trin \\
\hline & FT & 0.10 & 0.54 & 0.60 & 0.61 & 0.66 & $0.77^{*}$ & $0.82 *$ & $0.86^{*}$ & $0.89 *$ & $0.95 * *$ & $0.98 * *$ & 0.61 & 0.79 \\
\hline Beijing 2008 & FT & -0.05 & $0.51 *$ & $0.66^{* *}$ & $0.68 * *$ & $0.78 * *$ & $0.80 * *$ & $0.82 * *$ & $0.86^{* *}$ & $0.89 * *$ & $0.95 * *$ & $0.97^{* *}$ & $0.57 * *$ & 0.07 \\
\hline
\end{tabular}

$* p<0.05, * * p<0.001$.

rising values of the correlation coefficient $(r=0.77-0.98)$. The correlation values were identical in both examined Games and it is remarkable that after the $6^{\text {th }}$ hurdle was determined $67 \%(r=0.82)$ of the variance of the final time, while after the $10^{\text {th }}$ hurdle was determined $96 \%(\mathrm{r}=0.98)$ of the above variance. On the basis of the time data of the Mueller \& Hommel (1997) project the corresponding correlation coefficients in Athens 1997 can be calculated, which represent similar values $\left(r=0.84\right.$ and $r=0.97$ for $6^{\text {th }}$ and $10^{\text {th }}$ hurdle, respectively).

\section{Clearance Times}

The observed mean values of hurdle clearance times $(0.28 \pm 0.02 \mathrm{~s}$ to $0.33 \pm 0.01 \mathrm{~s})$ are in agreement with the findings of Mueller \& Hommel (1997) $(0.30 \pm 0.01 \mathrm{~s}$ to $0.31 \pm 0.02 \mathrm{~s})$ and of Graubner \& Nixdorf $(2011)(0.30 \pm 0.02 \mathrm{~s}$ to $0.33 \pm 0.01 \mathrm{~s})$. The absence of a significant relationship between hurdle clearance times and final time, in the present study, does not mean that the hurdle clearance times are not an indicator of the race performance. Contrariwise, a minimised clearance time is an indicator of high sprinting abilities and top technical level of the hurdle sprinters, and a prerequisite for the elite athletes for successful performance, for the reason that a fast hurdle clearance allows the maintaining of the achieved high horizontal velocity in between the hurdles (Salo et al., 1997).

\section{Run-in Phase}

The relative quantity of the run-in time was $0.089 \pm 0.003 \mathrm{~s}$ $(1-\mathrm{RTH} 10=1-0.911 \mathrm{~s})$ and was the same in both Games, Athens 2004 and Beijing 2008. This fact means that the trin contributed $9.9 \%$ to the formation of the final performance. This was in agreement with other studies (Graubner \& Nixdorf, 2011; Mueller \& Hommel, 1997; Brüggemann \& Glad, 1990), and on the basis of these time data the contribution of trin to the formation of the final performance in hurdle races in Seoul 1988 (9.3\%), in Athens 1997 (9.0\%) and Berlin $2009(8.8 \%)$ can be calculated.

The last part of the race is a net sprint running. Subtracting a distance of $1.05 \mathrm{~m}$ (which represents the approximate land- 
ing distance after the last hurdle) of the official distance of $10.50 \mathrm{~m}$, the runners are invited to cover an actual distance of $9.45 \mathrm{~m}$, attempting, initially, to carry out the transition from the acyclic movement of the last clearance stride into a cyclic motion (running stride) and then to increase the running velocity up to the finish. The run-in distance, although without hurdles, is not sufficient to develop maximum running velocity, so the achieving run-in average velocity is lower than the velocity in the other hurdle units (except the approach run and $9^{\text {th }}$ hurdle unit). In the present study the run-in average velocities were $8.42 \mathrm{~m} / \mathrm{s}$ and $8.24 \mathrm{~m} / \mathrm{s}$ in Athens 2004 and Beijing 2008, respectively. The corresponding velocities were $7.87 \mathrm{~m} / \mathrm{s}$ in Seoul 1988, $8.30 \mathrm{~m} / \mathrm{s}$ in Athens 1997 and $8.45 \mathrm{~m} / \mathrm{s}$ in Berlin 2009 (Graubner \& Nixdorf, 2011; Mueller \& Hommel, 1997; Brüggemann \& Glad, 1990).

\section{Relative Times}

Due to the different final performances in the various competitions, as a direct consequence are observed different values in their intermediate times. Thus, to study the temporal distribution of the competitive efforts during the hurdle races and to draw safe conclusions from a comparison among the various competitions, the relative temporal parameters (intermediate times normalised by the final time) were used.

In the present study, the mean values of the relative temporal parameters showed a similar race pattern of the hurdle finalists in both Olympic Games. It is remarkable that the time contribution of the first half of the race was slightly larger than the second one (RTH5 $=0.516$ in both Games). On the basis of the time data of top level competitions (Graubner \& Nixdorf, 2011; Mueller \& Hommel, 1997; Brüggemann $\&$ Glad, 1990) could be calculated and produced the corresponding values in Seoul 1988 (RTH5 = 0.512), in Athens 1977 (RTH5 = 0.514) and in Berlin 2009 (RTH5 = 0.516). Additionally, the duration of the hurdle units, as a whole, constituted the $70.8 \%$ of the total race time in both Games, Athens 2004 and Beijing 2008. Based again in calculations against the time data of Graubner \& Nixdorf (2011), Mueller \& Hommel (1997) and Brüggemann \& Glad (1990), could be estimated that the corresponding percentages were $72.0 \%$ in Seoul 1988, 70.8\% in Athens 1977 and 70.7\% in Berlin 2009. The remaining percentage, approximately $30 \%$, for formation of the final performance was shared between the first touchdown time $(\mathrm{RTH} 1=0.187$ to 0.204$)$ and the run-in time (Rtrin $=0.088$ to 0.093 ). The former one contributes $20.3 \%$ and the latter one $8.7 \%$ for formation of the final race performance, with slight variations on each side in the various races. All the above mentioned, based on the relative temporal parameters, suggest the existence of a common hurdle race pattern, regardless of the final performances in the various competitions. The main limitations of the present study are 1) the absence of physiological characteristics of the subjects (age, body composition, various anatomical characteristics, training experience ets), due to the lack of personal experimental design, 2) the absence of laser instruments for measurement of instantaneous velocities, as well as the no use of high speed cameras to accurate measurement of take-off and landing distances before and after the hur- dles. Future studies should be focused on linking detailed kinematic and kinetic parameters with the direct performance descriptors of the high level hurdle sprint, and corresponding studies could be conducted in the area of teenagers and young hurdlers.

\section{CONCLUSION}

From the direct performance descriptors examined in the present study, it is evident that there aren't any significant differences between the means of time parameters in $100-\mathrm{m}$ women hurdles at two consecutive Olympic Games. In summary, the most important findings are the following:

1. No existence of significant relationship between reaction time and race performance

2. Absence of a significant relationship between hurdle clearance times and race performance

3. Running acceleration from the start to $6^{\text {th }}$ hurdle

4. Identification of the decisive points of the race, especially from the $5^{\text {th }}$ to $10^{\text {th }}$ hurdle $(\mathrm{r}=0.77-0.98$ between the intermediate times and final performance)

5. After the $6^{\text {th }}$ hurdle is determined $67 \%$ of the variance of the final time, while after the $10^{\text {th }}$ hurdle $96 \%$ of the above variance

6. Finally, the main finding is the existence of a common race pattern in high level hurdle performance, regardless of the final performances in the various competitions. Approximately, to the formation of the race performance the approach run time contributes $19 \%$, the duration of the hurdle units, as a whole, $71 \%$ and the run-in time $10 \%$. Additionally, the time contribution of the first half of the race to the formation of the final performance is approximately equal to the second one $(51.6 \%$ vs $48.4 \%)$

In conclusion the findings of the present study can provide coaches and athletes with valuable quantitative information and offer them the possibility, on the basis of statistical models of technical parameters, to make effective interventions in the training process.

\section{ACKNOWLEDGEMENTS}

The authors gratefully acknowledge Prof. Svetoslav Ivanov, Mr. Evaggelos Antzakas and Mr. Nedialko Nedialkov for their assistance during the videotaping session.

\section{REFERENCES}

Brüggemann G.-P., Glad B. (1990). Time analysis of the 110 meters and 100 meters hurdles: Scientific Research Project at the Games of the XXIVth Olympiad-Seoul 1988, Final Report. New Studies in Athletics (supplement), 5, 91-131.

Coh, M. (1987). The analysis of the Jordanka Donkova's 100m hurdles world record. Fizicka Kultura (Belgrade), 41 (5), 351-353.

Coh M, Dolenec A. (1996). Three-dimensional kinematic analysis of the hurdles technique used by Brigita Bukovec. New studies in athletics, 11, 63-70. 
Graubner R, Nixdorf E. (2011). Biomechanical analysis of the sprint and hurdles events at the 2009 IAAF World Championships in Athletics. New studies in athletics, 26 (1-2), 19-53.

Hamlin, M. J., Hopkins, W. G., \& Hollings, S. C. (2015). Effects of altitude on performance of elite track-and-field athletes. International journal of sports physiology and performance, 10 (7), 881-887.

Hücklekemkes J. (1990). Model technique analysis sheets for the hurdles. Part VI: The Womens 100 m Hurdles. New studies in athletics, 5 (4), 33-58.

Iskra J, Coh M. (2006). A review of biomechanical studies in hurdle races. Kinesiologia Slovenica, 1, 84-102.

Mann R, Herman, J. (1985). Kinematic analysis of Olympic hurdle performance: women's 100 meters. International Journal of Sport Biomechanics, 1 (2), 163-173.

Marar L, Grimshaw P. (1993). A three-dimensional biomechanical analysis of sprint hurdles. Journal of Sports Sciences, 12, 174-175.

McDonald C, Dapena J. (1991a). Angular momentum in the men's 110-m and women's 100-m hurdles races. Medicine \& Science in Sports \& Exercise, 23 (12), 1392-1402.

McDonald C, Dapena J. (1991b). Linear kinematics of the men's 110-m and women's 100-m hurdles races. Medicine \& Science in Sports \& Exercise, 23 (12), 1382-1391.

McLean B. (1994). The biomechanics of hurdling: Force plate analysis to assess hurdling technique. New studies in athletics, 4, 55-58.
Mueller H, Hommel H. (1997). Biomechanical research project at VIth World Championships in Athletics, Athens 1997: preliminary report. New studies in athletics, 12 (2/3), 43-73.

Ryu J. K., Chang J. K. (2011). Kinematic Analysis of the Hurdle Clearance Technique used by World Top Class Women's Hurdler. Korean Journal of Sport Biomechanics, 21 (2), 131-140.

Salo A, Grimshaw P. N., Marar L. (1997). 3-D biomechanical analysis of sprint hurdles at different competitive levels. Medicine and science in sports and exercise, 29 (2), 231-237.

Stein N. (2000). Reflections on a change in the height of the hurdles in the women's sprint hurdles event. New studies in athletics, 15 (2), 15-20.

Wang, J. H., \& Li., N. (2000). Analysis of the technique of hurdle step and run between hurdles. Journal of Wuhan institute of physical education, 34 (1), 92-94.

Ward-Smith, A. (1997). A mathematical analysis of the bioenergetics of hurdling. Journal of Sports Sciences, 15 (5), 517-526.

Yoshimoto, T., Takai, Y., \& Kanehisa, H. (2016). Acute effects of different conditioning activities on running performance of sprinters. SpringerPlus, 5(1), 1203.

Normand, J. M., Wolfe, A., \& Peak, K. (2017). A Review of Early Sport Specialization in Relation to the Development of a Young Athlete. International Journal of Kinesiology and Sports Science, 5(2), 37-42. 